\title{
Article \\ Improved Design and Thermo-Mechanical Verification of Deflection Magnet Beam Collimator of EAST-NBI System
}

\author{
Ling Tao ${ }^{1, *}$, Yuanlai $\mathrm{Xie}^{2}{ }^{2}$, Chundong $\mathrm{Hu}^{2}$, Wei $\mathrm{Yi}^{2}$ and Lizhen Liang ${ }^{2}$ \\ 1 School of Energy and Power Engineering, Nanjing University of Science and Technology, \\ Nanjing 210094, China \\ 2 Institute of Plasma Physics, Chinese Academy of Sciences, Hefei 230031, China; \\ laurrence@ipp.ac.cn (Y.X.); cdhu@ipp.ac.cn (C.H.); yiwei@ipp.ac.cn (W.Y.); lzliang@ipp.ac.cn (L.L.) \\ * Correspondence: taoling@163.com or taoling@njust.edu.cn
}

check for updates

Citation: Tao, L.; Xie, Y.; Hu, C.; Yi, W.; Liang, L. Improved Design and Thermo-Mechanical Verification of Deflection Magnet Beam Collimator of EAST-NBI System. Energies 2022, 15, 1911. https:// doi.org/10.3390/en15051911

Academic Editor: Michael Liberman

Received: 25 January 2022

Accepted: 22 February 2022

Published: 5 March 2022

Publisher's Note: MDPI stays neutral with regard to jurisdictional claims in published maps and institutional affiliations.

Copyright: (C) 2022 by the authors. Licensee MDPI, Basel, Switzerland. This article is an open access article distributed under the terms and conditions of the Creative Commons Attribution (CC BY) license (https:// creativecommons.org/licenses/by/ $4.0 /)$.

\begin{abstract}
The deflection magnet (DM) is the most important component of the Neutral Beam Injection (NBI) system of Experimental Advanced Superconducting Tokamak (EAST), which can magnetically deflect the un-neutralized charged particles after the neutralized process of the beam is extracted from the ion source, and then form a neutral beam injected into the tokamak. Under the operating conditions of the NBI system, by using the thermocouple monitoring system in the experiment, it can be found that the currently operating DM beam collimator has a quite high temperature rise. It is necessary to redesign the DM beam collimator to improve its heat transfer performance. The parallel arrangement of multiple rows of tubes is proposed as the basic method for the redesign of the beam collimator of DM, the thermal-fluid-structure analysis model of this redesign model is established and its temperature field, pressure field and stress field are analyzed. Taking the surface temperature of the beam collimator, the overall dimension after the total tube combination and the pressure drop of the whole structure of collimator as the optimization objectives, and setting the fluid velocity, the tube's inner diameter and the number of tube rows as the design variables, the optimized design scheme of the beam collimator structure is obtained. From the results of simulation, the new structure can better meet the operation requirements of DM, and its maximum temperature rise is well controlled, which is expected to meet the long pulse operation requirements of the NBI system. The proposed simulation and design optimization method can provide a certain reference for the design and optimization of other high-heat-flux structures in complex large-scale neutral beam systems in the future.
\end{abstract}

Keywords: neutral beam injection; deflection magnet; design optimization; thermal-fluid-structure coupling; heat transfer performance

\section{Introduction}

The Experimental Advanced Superconducting Tokamak (EAST) has achieve more than $100 \mathrm{~s}$ pulse length to maintain the plasma condition. As one of the main means of auxiliary heating and maintenance of plasma on the magnetic confinement controlled nuclear fusion experimental device [1], Neutral Beam Injection (NBI) heating is shown in Figure 1. The deflection magnet (DM) is one of the key components of the NBI system concerning the formation of the neutral particle beam [2]. There are still some un-neutralized charged particles after the neutralizer, and the beam mixed with the residual ions will enter the area of the DM. The residual ions can be stripped out of the beam passage by the DM, and they then form a neutral beam that can be injected into the tokamak. According to the different sources of the force on the charged particles during deflection, the deflection methods can be divided into magnetic deflection and electrical deflection [3-5]. Currently, the most mature and widely used is the magnetic deflection method. The EAST-NBI system also uses the magnetic deflection method, and the detail arrangement of its DM is shown in 
Figure 2 [6]; beside the body of deflection magnet yoke, it is composed of coil, magnetic pole shield, shielding bar, shutter and the entrance and exit collimators [7]. Among those, the entrance and exit collimators are, respectively, located on both sides of the DM, and their basic function is to absorb the divergent particles of the beam to prevent them from bombarding the deflection magnet itself.

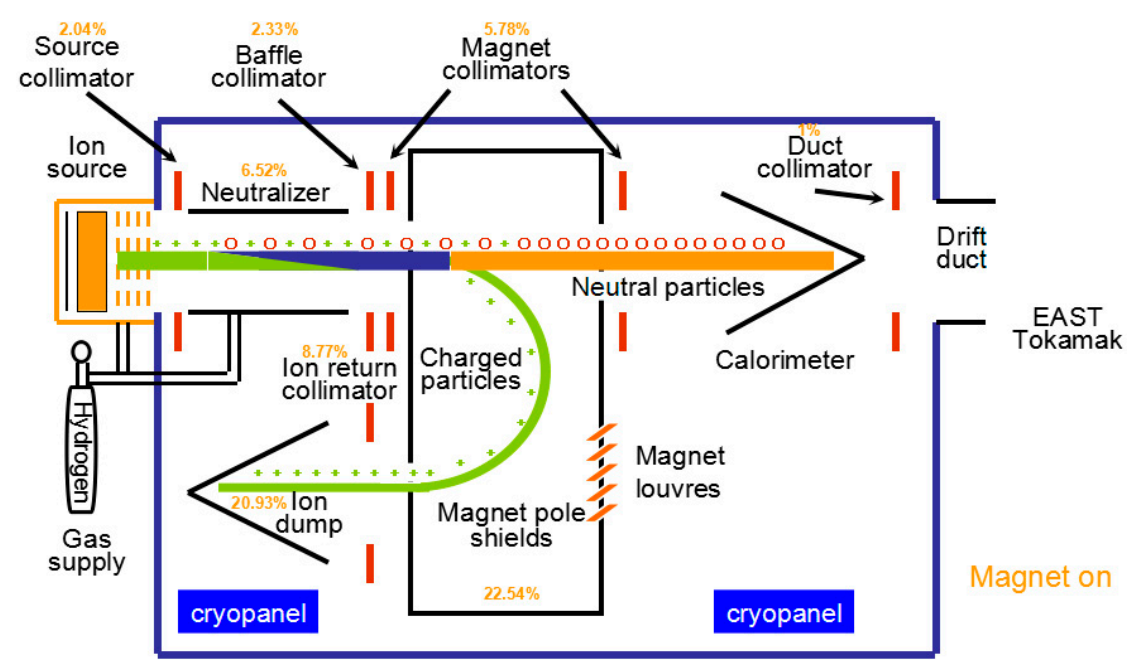

Figure 1. Basic structural diagram of the EAST tokamak NBI system.

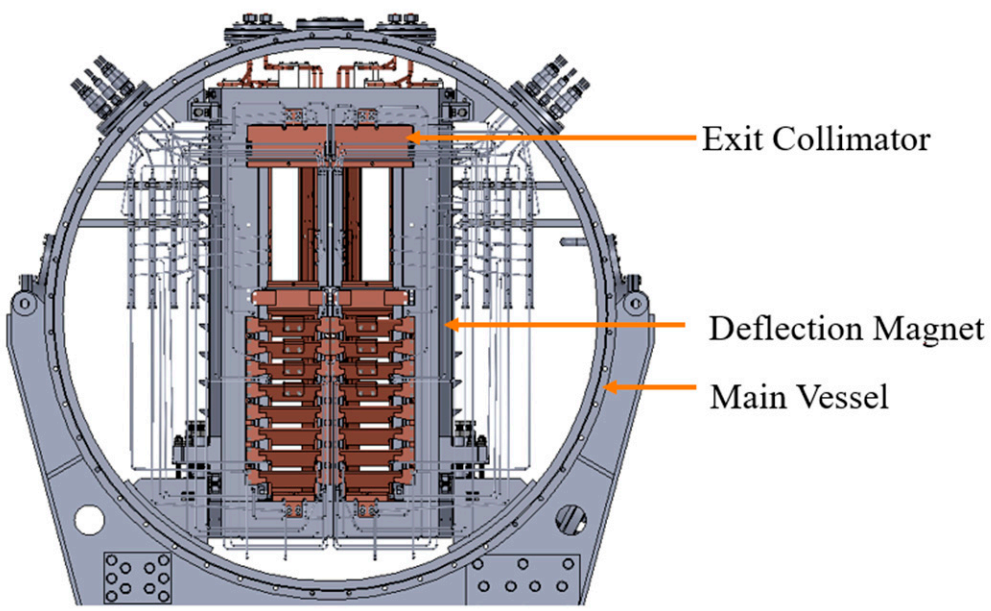

Figure 2. Structure and layout of DM inside the second spool of the NBI system.

The original design of DM beam collimators adopts the inertial heat exchange mode, and the stainless steel cooling water pipe is fixed inside the copper plate by vacuum brazing, resulting in certain contact thermal resistance and a poor heat exchange effect. According to the experimental operation results of EAST-NBI (more than $65 \mathrm{Kev}$ ), the original design of DM beam collimators will cause the problem that the temperature rise exceeds the upper limit of the system, resulting in the suspension of the experimental operation; in the later stage of the experiment, ablation spots can be seen in parts after disassembly. Therefore, in order to improve the pulse operation time and realize the operation requirements of pulses greater than $100 \mathrm{~s}$ [8] or even longer, the structure of DM beam collimators must be redesigned and optimized. Referring to the design scheme of nuclear fusion-related high heat flux components, there are many kinds of improved structure design scheme that can be used to strengthen heat exchange of collimators of DM [9-12]. In order to ensure the reliability of the structure and prevent the beam transmission from causing particle bombardment to other components, especially the cryogenic pump behind it, the beam collimators are still recommended to adopt the plate structure, according to the 
experience of EAST-NBI and DIII-D NBI [13,14]. According to the physical calculation of beam transmission characteristics, the value of the heat flux deposited on the surface of the collimators is no more than $2 \mathrm{MW} / \mathrm{m}^{2}$; it is preliminarily planned to redesign the collimators as a big plate-shaped structure which is lapped to splice by some parallelarranged small plates shaped with a straight hole inside.

Here the efficient thermo-mechanical coupling simulation method is used to optimize the new design scheme and verify its thermo-mechanical performance, which has been widely used in design and optimization of nuclear fusion-related high heat flux components [15-17]. Wang et al. [14] verified that the absolute collimator could better meet the design criteria of surface temperatures $(<573.15 \mathrm{~K})$ and a non-thermal ratcheting pulsed operation scenario by using ANSYS CFX software. Muri et al. [18] simulated and tested the thermo-mechanical performance of 1D-carbon-carbon fiber composite prototypes for the SPIDER (Source for Production of Ion of Deuterium Extracted from RF plasma) diagnostic calorimeter. Mistry et al. [19] evaluated the reliability of heat transfer elements (HTEs) in the worst operational condition by the thermal-structural analysis, and pointed that the second calorimeter for the Neutral Beam Indian Test Facility composed with curved V-type HTE models could meet the required number of thermal cycles (fatigue cycles) for the designed case. Wei et al. [20] gave the thermo-mechanical design of the neutralizer for the CRAFT (Comprehensive Research Facility for Fusion Technology) negative NBI system, and obtained the appropriate combination of operating parameters. Peng et al. [21] did steady state thermo-hydraulic and thermo-mechanical elastic analyses for the water cooled divertor of CFETR (China Fusion Engineering Test Reactor), one of the most challenging components of CFETR, to verify the feasibility of the cooling structure, and gave an optimal mass rate as a compromise between the heat load bearing and the pumping power based on analysis results. So for the new design of DM collimators, it is very important to perform the thermo-hydraulic and thermo-mechanical analysis to carry out structural optimization and obtain the optimal structure.

\section{Design Scheme of New Deflection Magnet Beam Collimators}

According to the area of vacuum chamber and the size of the body of deflection magnet yoke, the design size of the components left at the inlet is that: The length direction must be at least greater than $0.12 \mathrm{~m}$, and the distance from the beam incoming side should be $0.36 \mathrm{~m}$; that is, the restriction on the installation position of the beam and magnetic finger in the height and width directions should not be greater than $0.24 \mathrm{~m}$. It is planned that the newly designed beam collimators at the DM entrance and exit will increase the heat exchange performance by using the parallel arrangement of multiple rows of tubes. The preliminary structural design is shown in Figure 3. The exit and entrance beam collimators have a similar structure, and only the installation positions are different (shown in Figure 2). Thus, only the entrance beam collimator is used as an example for description here and is called "beam collimator" for short. Later, combined with specific analysis and optimization, the corresponding design parameters of the two beam collimators will be given, respectively. The beam collimator is designed as a flat plate structure above the beam channel $(0.12 \mathrm{~m} \times 0.48 \mathrm{~m})$, which can prevent the beam from transmitting to other parts. The main target plate is made of oxygen free copper, and formed by overlapping several small plates in the front and back, and the front and back of two sides of the cooper plate are arranged support structures which are fixed on the body of the DM with bolts, as shown in Figure 3. Considering the limitation of the space area, the main pipe can only be arranged outside the DM and the branch pipes linked with the stainless steel circular pipe to avoid the branch pipes interfering with each other, and the joint between different materials is fixed by vacuum brazing. It is required to leave about $0.007 \mathrm{~m}$ welding space between each two pipes. Referring to the physical analysis of beam transmission, the heat flux deposition on the entrance beam collimator is symmetrically distributed, as shown in Figure 4 (the quarter of the whole profile). 


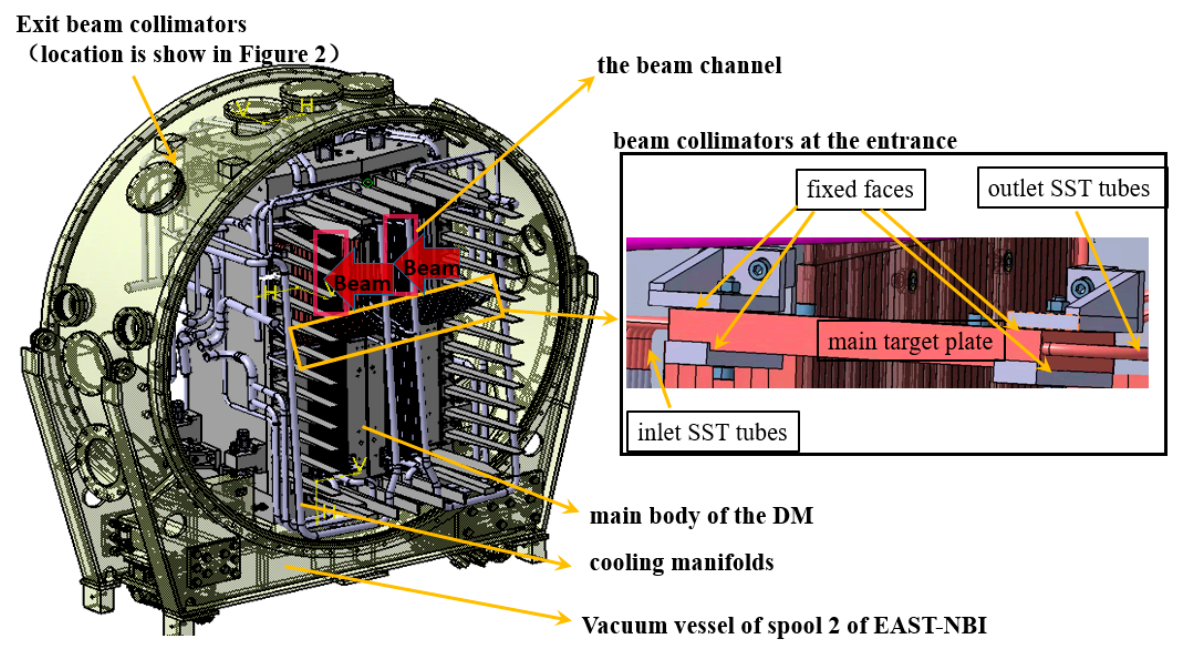

Figure 3. The redesign scheme of beam collimators for the EAST-NBI system.

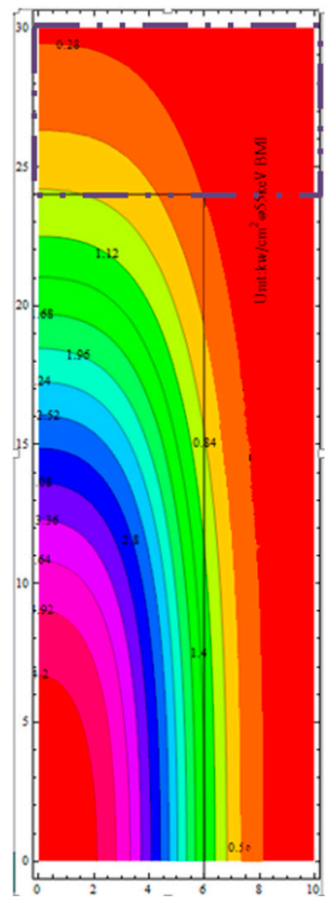

Figure 4. Heat flux deposition distribution of entrance collimators (1/4 part) on vertical direction.

The power deposition distribution on the collimator surface on one side of the centreline is in the dotted box. The constraints of the model optimization design are as follows: (1) The number of pipe rows is an integer. Due to the structural requirements, the value range of the pipe row diameter corresponding to a different number of pipe rows is different, but it shall be less than $0.0065 \mathrm{~m}$, and the corresponding plate width of the pipe bundle shall not be less than $0.01 \mathrm{~m}$; (2) the pressure drop of the tube bundle shall not be greater than $0.7 \mathrm{MPa}$; (3) the overall structural width shall not be greater than $0.136 \mathrm{~m}$, and the plate thickness shall not be greater than $0.05 \mathrm{~m}$; (4) the maximum temperature of the heat flow surface shall not exceed $573.15 \mathrm{~K}$; in addition, the deformation of the structure shall not exceed $0.002 \mathrm{~m}$, and the stress shall not exceed the required stress of oxygen free copper (plate structure) and stainless steel (branch pipe and support), which are $81 \mathrm{MPa}$ and $111 \mathrm{MPa}$, respectively (with safety factor of 3). 


\section{Numerical Analysis Model of DM Beam Collimators}

In the simulation process of the DM beam collimators, the following assumptions are used: (1) The fluid is a steady flow with constant physical properties and no internal heat source; (2) the fluid is incompressible; (3) the natural convection and thermal radiation are ignored. Considering that the structural deformation is small and the influence on fluid flow and heat transfer can be ignored, the unidirectional coupling analysis method is adopted in the numerical simulation in this paper; that is, firstly, the thermal-flow analysis model is established to calculate the transient temperature distribution and flow field pressure distribution of the collimator; on this basis, the transient structural analysis model by using the finite element method is established, and the temperature load and the fluid-structure coupling surface's fluid pressure at each time are transmitted to the transient structural analysis model to calculate the structural deformation and stress. The thermo-hydraulic analysis model is shown in Table 1.

Table 1. Basic equations of fluid and heat transfer [22-25].

\begin{tabular}{|c|c|}
\hline $\begin{array}{c}\text { Mass Conservation } \\
\text { Equation }\end{array}$ & $\frac{\partial(\rho u)}{\partial x}+\frac{\partial(\rho v)}{\partial y}+\frac{\partial(\rho w)}{\partial z}=0$ \\
\hline \multirow{3}{*}{$\begin{array}{l}\text { Momentum Conservation } \\
\text { Equation }\end{array}$} & $\begin{array}{cc}\frac{\partial(\rho u)}{\partial t}+\frac{\partial(\rho u u)}{\partial x}+\frac{\partial(\rho v u)}{\partial y}+\frac{\partial(\rho w u)}{\partial z}=\rho F_{x} & -\frac{\partial p}{\partial x}+\frac{\partial}{\partial x}\left(2 \mu \frac{\partial u}{\partial x}+\bar{\lambda} \operatorname{div} U\right) \\
+\frac{\partial}{\partial y}\left[\mu\left(\frac{\partial v}{\partial x}+\frac{\partial u}{\partial y}\right)\right]+\frac{\partial}{\partial z}\left[\mu\left(\frac{\partial w}{\partial x}+\frac{\partial u}{\partial z}\right)\right]\end{array}$ \\
\hline & $\begin{aligned} \frac{\partial(\rho v)}{\partial t}+\frac{\partial(\rho u v)}{\partial x}+\frac{\partial(\rho v v)}{\partial y}+\frac{\partial(\rho w v)}{\partial z}= & \rho F_{y}-\frac{\partial p}{\partial y}+\frac{\partial}{\partial x}\left[\mu\left(\frac{\partial v}{\partial x}+\frac{\partial u}{\partial y}\right)\right] \\
& +\frac{\partial}{\partial y}\left(2 \mu \frac{\partial v}{\partial y}+\bar{\lambda} \operatorname{div} U\right)+\frac{\partial}{\partial z}\left[\mu\left(\frac{\partial w}{\partial y}+\frac{\partial v}{\partial z}\right)\right]\end{aligned}$ \\
\hline & $\begin{aligned} \frac{\partial(\rho w)}{\partial t}+\frac{\partial(\rho u w)}{\partial x}+\frac{\partial(\rho v w)}{\partial y}+\frac{\partial(\rho w w)}{\partial z}= & \rho F_{z}-\frac{\partial p}{\partial z}+\frac{\partial}{\partial x}\left[\mu\left(\frac{\partial w}{\partial x}+\frac{\partial u}{\partial z}\right)\right] \\
& +\frac{\partial}{\partial y}\left[\mu\left(\frac{\partial w}{\partial y}+\frac{\partial u}{\partial z}\right)\right]+\frac{\partial}{\partial z}\left(2 \mu \frac{\partial w}{\partial z}+\bar{\lambda} \operatorname{div} U\right)\end{aligned}$ \\
\hline $\begin{array}{l}\text { Energy Conservation } \\
\text { Equation }\end{array}$ & $\begin{aligned} \frac{\partial(\rho T)}{\partial t}+\frac{\partial(\rho u T)}{\partial x}+\frac{\partial(\rho v T)}{\partial y}+\frac{\partial(\rho w T)}{\partial z} & =S_{T}+\frac{\partial}{\partial x}\left(\frac{\lambda}{C_{p}} \frac{\partial T}{\partial x}\right) \\
& +\frac{\partial}{\partial y}\left(\frac{\lambda}{C_{p}} \frac{\partial T}{\partial y}\right)+\frac{\partial}{\partial z}\left(\frac{\lambda}{C_{p}} \frac{\partial T}{\partial z}\right)\end{aligned}$ \\
\hline$k$-Equation & $\frac{\partial(\rho k)}{\partial t}+\frac{\partial\left(\rho k u_{i}\right)}{\partial x_{i}}=\frac{\partial}{\partial x_{j}}\left(\left(\mu+\frac{\mu_{t}}{\sigma_{k}}\right) \frac{\partial k}{\partial x_{j}}\right)+G_{k}+G_{b}-\rho \varepsilon-Y_{M}+S_{K}$ \\
\hline $\mathcal{E}$-Equation & $\frac{\partial(\rho \varepsilon)}{\partial t}+\frac{\partial\left(\rho \varepsilon u_{i}\right)}{\partial x_{i}}=\frac{\partial}{\partial x_{j}}\left(\left(\mu+\frac{\mu_{t}}{\sigma_{\varepsilon}}\right) \frac{\partial \varepsilon}{\partial x_{j}}\right)+C_{1 \varepsilon} \frac{\varepsilon}{k}\left(G_{k}+C_{3 \varepsilon} G_{b}\right)-C_{2 \varepsilon} \rho \frac{\varepsilon^{2}}{k}-R_{\varepsilon}+S_{\varepsilon}$ \\
\hline
\end{tabular}

Where $\rho$ is fluid density, and $u, v, w$ are the components of fluid velocity vector $U$ in $x, y, z$ coordinate directions, respectively. $F_{\mathrm{x}}, F_{\mathrm{y}}$ and $F_{z}$ are the components of the volume force on the micro element in the $x, y, z$ directions. $\mu$ is the dynamic viscosity of the fluid, $\bar{\lambda}$ is the second molecular viscosity of the fluid, $p$ is the fluid pressure, $T$ is the fluid temperature, $\lambda$ is the thermal conductivity of the fluid, and $S_{T}$ is the viscous dissipation term. $C_{\mu}, C_{1 \varepsilon}$, $C_{2 \varepsilon}$ and $C_{3 \varepsilon}$ are model constants, $\sigma_{k}$ and $\sigma_{\varepsilon}$ are the turbulent Prandtl numbers of $k$ and $\varepsilon$ equations. $S_{k}$ and $S_{\varepsilon}$ are the user-defined parameters [20-23]. $G_{k}$ is the generation term of turbulent kinetic energy caused by average velocity gradient, and $G_{b}$ is the generation term of turbulent kinetic energy caused by buoyancy.

Among them, due to the large variation of velocity in the boundary layer, more computational grids are needed to analyze the cooling pipe near the pipe wall. The resolution of the grid near the wall can be measured by the dimensionless wall distance $y+$.

$$
u^{+}=\frac{\bar{u}}{u_{\tau}}, \mathrm{y}^{+}=\frac{y \rho u_{\tau}}{\mu}, u_{\tau}=\sqrt{\frac{\tau_{w}}{\rho}}
$$


where $u_{\tau}$ is the friction velocity, $\bar{u}$ is mean velocity of fluid; $u^{+}$is dimensionless velocity of fluid, $\tau_{w}$ is wall shear stress, $\mathrm{y}$ is the normal distance and $\tau_{w}$ is a boundary condition and is calculated as:

$$
\tau_{w}=\rho u^{*} u_{\tau}
$$

Both of the friction velocities $\left(u_{\tau}, u^{*}\right)$ are blended between the viscous sub-layer and the logarithmic region.

$$
u^{*}=\left[\left(\frac{\mu U_{\tan }}{\Delta y}+C_{\mu}^{1 / 2} \rho k\right) \frac{1}{\rho}\right]^{1 / 2}
$$

For the friction velocity $u_{\tau}$, the following formulation is used

$$
u_{\tau}=U_{\tan }\left[\left(u_{\text {lam }}^{+}\right)^{-4}+\left(u_{\text {turb }}^{+}\right)^{-4}\right]^{1 / 4}
$$

Here, the Menter-Lechner near-wall treatment is adopted, and the main idea of the Menter-Lechner near-wall treatment is to add a source term to the transport equation of the turbulence kinetic energy $k$ that accounts for near-wall effects. The additional source term $S_{\text {near-wall }}$ is active only in the viscous sub-layer here. It automatically becomes zero in the logarithmic region.

In order to describe the structural vibration of the collimator, the finite element vibration model under the fluid pressure and the thermal effect is established as

$$
\mathbf{M}_{s} \ddot{\boldsymbol{\delta}}_{S}+\mathbf{C}_{s} \dot{\boldsymbol{\delta}}_{S}+\mathbf{K}_{s} \boldsymbol{\delta}_{s}=\mathbf{F}_{S}
$$

where $\mathbf{M}_{s}, \mathbf{C}_{s}$ and $\mathbf{K}_{s}$ are the global mass, damping and stiffness matrices of the collimator, respectively. $\boldsymbol{\delta}_{S}$ is the global nodal displacement vector and $\mathbf{F}_{\mathcal{S}}$ is the global load vector (including the pressure on the fluid-structure coupling surface and the thermal stress).

Due to the different discretization methods and grid division of structural field and flow field, the grids of these two models do not match, which requires the interpolation of coupling physical quantities (the temperature and the fluid-structure coupling surface's fluid pressure) during unidirectional coupling analysis to ensure the transmission of coupling information (such as the local interpolation represented by the mapping point method and constant volume conversion method, and the global interpolation represented by the radial basis function method).

\section{Simulation and Verification of Thermo-Mechanical Performance of the New Scheme}

The parametric optimization method uses the sampling technology to collect the design variable sampling points, calculate the response results of each sampling point and use the quadratic difference function to construct the response surface surrogate model of the design space. Then the design optimization based on the surrogate model is completed, and the optimal design scheme is obtained. Finally, the optimal design scheme is verified by using the original thermal-fluid-structure coupling analysis model. The selection of the design parameters is mainly based on the influence on the heat exchange and cooling performance. For the design shown in Figure 3, in order to obtain the best heat exchange performance, comprehensively considering the design constraints (1)-(4), the tube bundle diameter, the number of tube rows and the inlet flow rate are selected as the design variables. Setting the tube bundle diameter $(0.0035 \mathrm{~m}, 0.004 \mathrm{~m}, 0.0045 \mathrm{~m}, 0.005 \mathrm{~m}, 0.0055 \mathrm{~m}, 0.006 \mathrm{~m}$, $0.0065 \mathrm{~m}, 0.007 \mathrm{~m}$ and $0.0075 \mathrm{~m}$ ), the number of tube rows as the integer value (2-10), the product of the number of tube rows and the plate width corresponding to the tube bundle diameter is less than or equal to $0.136 \mathrm{~m}$ (maximum design width), and the inlet flow rate is $0.1 \sim 6 \mathrm{~m} / \mathrm{s}$, respectively; different design schemes can be obtained. There are four objective functions, including the temperature rise of the heat-loaded surface, the pressure drop between the inlet and the outlet, the Von Mises stress of different parts with different materials and the space size, described in Section 2. The corresponding analysis is carried out by using the thermal-fluid-structure coupling model described in Section 3, and based 
on the parametric optimization analysis, the optimal design scheme meeting the design requirements can be obtained by comprehensively considering the engineering feasibility and economy as follows: (1) The entrance beam collimator-the minimum flow velocity is $4 \mathrm{~m} / \mathrm{s}$, and the diameter of each tube is $0.0065 \mathrm{~m}$, a total of three pipes are required, the maximum spacing between each tube is $0.046 \mathrm{~m}$ and the diameter of the main tube is $0.011 \mathrm{~m}$; (2) the outlet collimators - the minimum flow velocity is $4 \mathrm{~m} / \mathrm{s}$, the diameter of each tube is $6.5 \mathrm{~mm}$, a total of four pipes are required, the maximum spacing between each tube is $0.04 \mathrm{~m}$ and the diameter of the main tube is $0.0127 \mathrm{~m}$. The basic flow chart of simulation and optimization is shown as the Figure 5.

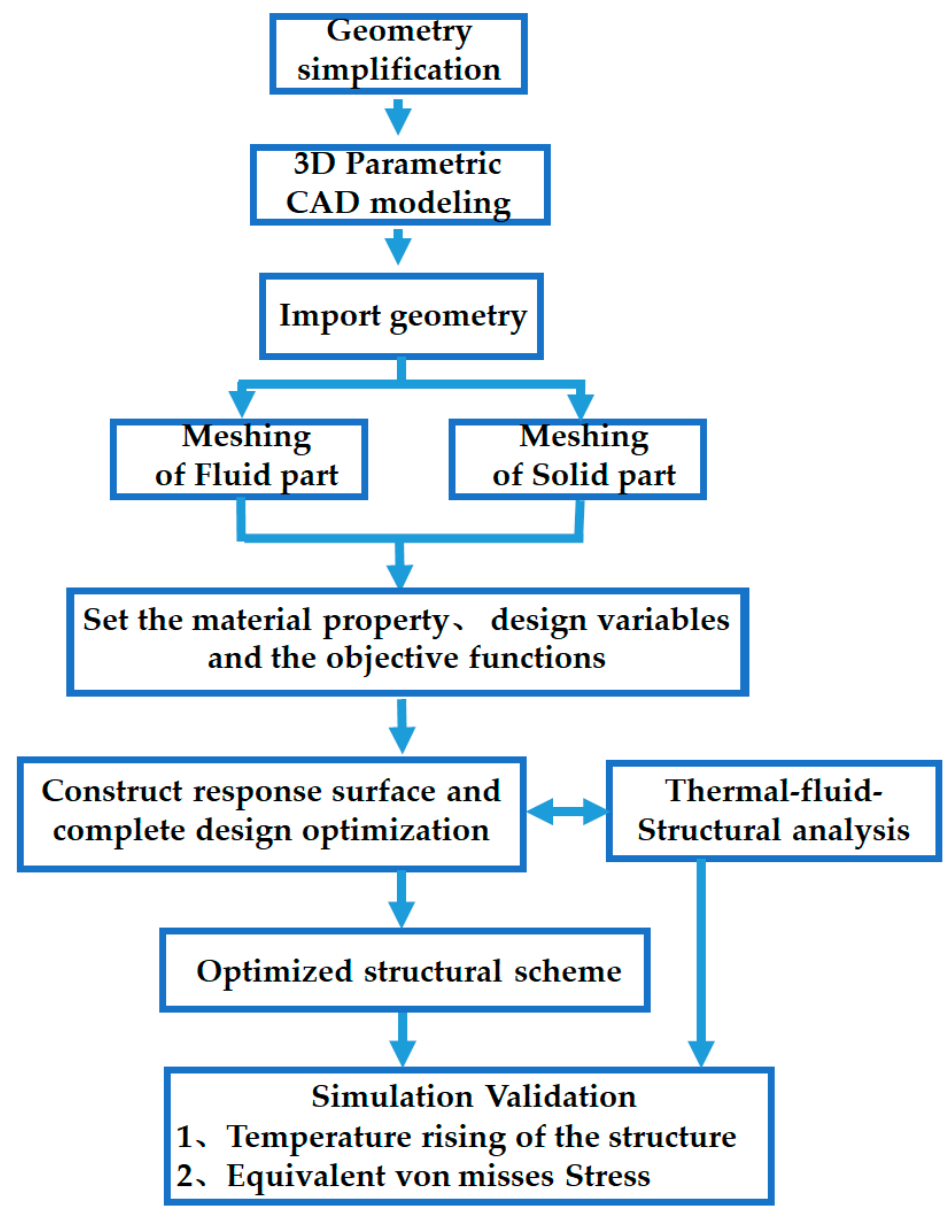

Figure 5. The basic flow chart of simulation and optimization.

For the optimized structural scheme, taking the entrance beam collimator as an example, the detailed analysis results of heat transfer performance and structural stress are given here. During the simulation process, the main part of the copper plates and the fluid areas adopt TGrid mesh, the inflated layers in the cooling pipe are set, which can make the calculation near the wall more realistic, and the Menter-Lechner near-wall treatment is chosen to describe the near-wall condition. For this optimized structure of entrance collimator, the grid independence has been verified. Under the current calculation grid state of 6.49 million, the change of surface temperature rise is about $\pm 1 \mathrm{~K}$, and the error of numerical simulation results is within $5 \%$. The thermodynamic parameters of oxygen free copper at $293 \mathrm{~K}$ are as follows: The thermal conductivity is $387.6 \mathrm{~W} / \mathrm{m} \cdot \mathrm{K}$, the specific heat is $390 \mathrm{~J} / \mathrm{kg} \cdot \mathrm{K}$, the density is $8930 \mathrm{~kg} / \mathrm{m}$ and the maximum surface temperature TCR $=573 \mathrm{~K}$; the thermodynamic parameters of the outer stainless steel pipe are: The thermal conductivity is $16.27 \mathrm{~W} / \mathrm{m} \cdot \mathrm{K}$, the specific heat is $470 \mathrm{~J} / \mathrm{kg} \cdot \mathrm{K}$ and the density is $8030 \mathrm{~kg} / \mathrm{m}^{3}$. Set the inlet water temperature as $293 \mathrm{~K}$ and the inlet flow velocity as $4 \mathrm{~m} / \mathrm{s}$. The thermodynamic parameters of the water in this state are: Specific heat of $4.183 \mathrm{~kJ} /(\mathrm{kg} \cdot \mathrm{K})$, density 
of $998.2 \mathrm{~kg} / \mathrm{m}^{3}$ and viscosity coefficient of $0.001006 \mathrm{~N} . \mathrm{s} / \mathrm{m}^{2}$, during the simulation; the physical parameters of material are listed as shown in the Table 2.

Table 2. Material physical parameters.

\begin{tabular}{ccc}
\hline \multicolumn{2}{c}{ Material Physical Parameter } & Relational Expression Variation with Temperature [26] \\
\hline \multirow{2}{*}{ Copper } & Specific heat $(\mathrm{J} / \mathrm{kg} \cdot \mathrm{K})$ & $C_{P}=372.54105+0.0409 T+4.2796 \times 10^{-5} T^{2}$ \\
& Density $\left(\mathrm{kg} / \mathrm{m}^{3}\right)$ & 8930 \\
& Thermal conductivity $(\mathrm{W} / \mathrm{m} \cdot \mathrm{K})$ & $\lambda=421.47246-0.07225 T+2.64976 \times 10^{-6} T^{2}$ \\
304 stainless steel & Specific heat $(\mathrm{J} / \mathrm{kg} \cdot \mathrm{K})$ & 470 \\
& Density $\left(\mathrm{kg} / \mathrm{m}^{3}\right)$ & 8030 \\
& Thermal conductivity $(\mathrm{W} / \mathrm{m} \cdot \mathrm{K})$ & 16.27 \\
Water & Specific heat $(\mathrm{J} / \mathrm{kg} \cdot \mathrm{K})$ & $C_{p}=10608.87995-55.7362 T+0.15919 T^{2}-1.49398 \times 10^{-4} T^{3}$ \\
& Density $\left(\mathrm{kg} / \mathrm{m}^{3}\right)$ & $\rho=150.99277+7.54409 T-0.02122 T^{2}+1.82226 \times 10^{-5} T^{3}$ \\
& Thermal conductivity $(\mathrm{W} / \mathrm{m} \cdot \mathrm{K})$ & $\lambda=-0.51402+0.00532 T-3.35719 \times 10^{-6} T^{2}-6.23349 \times 10^{9} T^{3}$ \\
& Viscosity coefficient $(\mathrm{kg} / \mathrm{m} \cdot \mathrm{s})$ & $\mu=0.11157-9.51523 \times 10^{-4} T+2.7249 \times 10^{-6} T^{2}-2.61107 \times 10^{-9} T^{3}$ \\
\hline
\end{tabular}

From Figure 2, the entrance collimator is fixed at the inlet of DM with an inclination of about 88 degrees, the deposited heat flux value on the surface of collimator decreases and, corresponding to the vertical direction (as shown in Figure 3), is much less than $2 \mathrm{MW} / \mathrm{m}^{2}$, and the maximum value is only $1.04 \mathrm{mw} / \mathrm{m}^{2}$; the approximate heat flux distribution on the corresponding surface is shown in Figure 6. One could find that the heat flux distribution profile on the heat-loaded surface in Figure 6 has the same trend with the beam profile as in Figure 3. With an inclined angle factor, the value of heat flux density per unit area was effectively reduced, and meanwhile, there is no heat flux distribution in other locations except the loaded surface. The grid layout is shown in Figure 7, and the details of the boundary layer mesh where a single branch pipe joins the main pipe are shown in the enlarged view; a total of 12 boundary layers are set. The y plus varying with the length of the cooling tubes is shown in Figure 8. The different colors in Figure 8 represent different pipe branches from inside to outside, respectively, and three branches have different average y plus values. The total average $y+$ corresponding to the boundary layer is about $4 \sim 5$, which meets the calculation accuracy requirements and is applicable to the current set of Menter-Lechner near-wall treatment.

Total surface heat flux

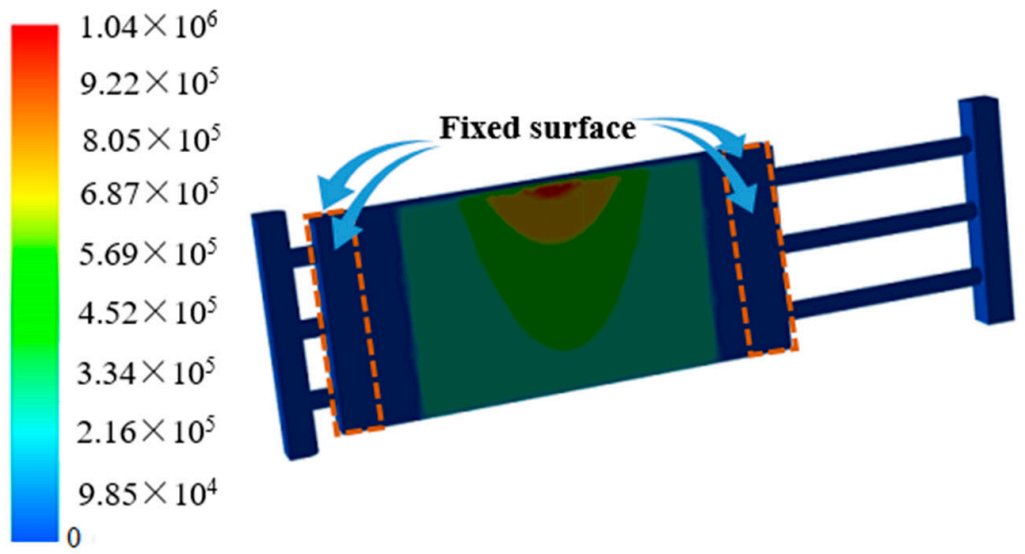

Unit: $\mathbf{W} / \mathbf{m}^{2}$

Figure 6. The heat flux profile of the entrance collimator.

The maximum temperature, flow velocity and pressure drop of the optimal design scheme for the collimator at the entrance on the above working conditions and parameters are shown in Figures 9 and 10. In Figure 9, the maximum temperature of the heat-loaded surface increases rapidly in the first $20 \mathrm{~s}$, and then the rate slows and becomes nearly steady. The maximum temperature is nearly $335 \mathrm{~K}$, which means at the corresponding cooling 
condition, the structure has the potential to withstand a more than $100 \mathrm{~s}$ longer pulse bombardment. The average velocity is $3 \sim 4 \mathrm{~m} / \mathrm{s}$, and there is a rapid change of velocity at the inlet and outlet of the structure, and the maximum value of local speed (at the inlet and outlet of branch pipe) can reach $6 \mathrm{~m} / \mathrm{s}$, but in the heat exchange area, the velocity keeps quite steady, as shown in Figure 10a. The corresponding pressure drop between the inlet and the outlet is only $0.03 \mathrm{MPa}$, as shown in Figure $10 \mathrm{~b}$. The maximum velocity and pressure drop appearance is at the tube near the outlet; meanwhile, the corresponding relationship gradually increases with the distance between the cooling tubes and the inlet, which is the main feature of Z-shaped cooling tube bundles.

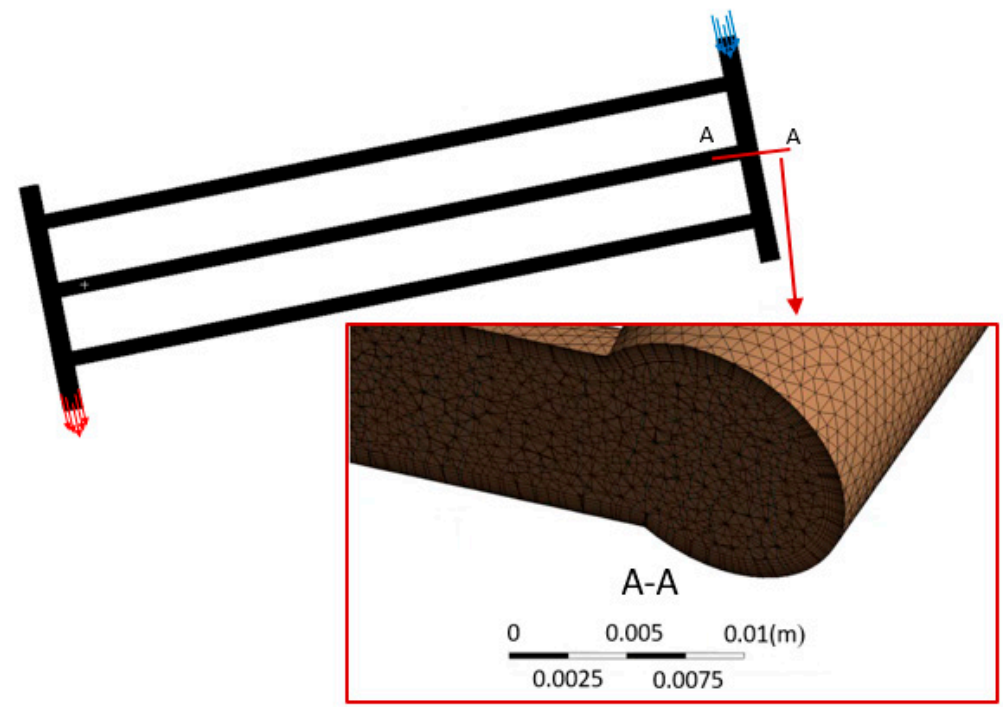

Figure 7. The typical mesh of the inflation for cooling tubes.

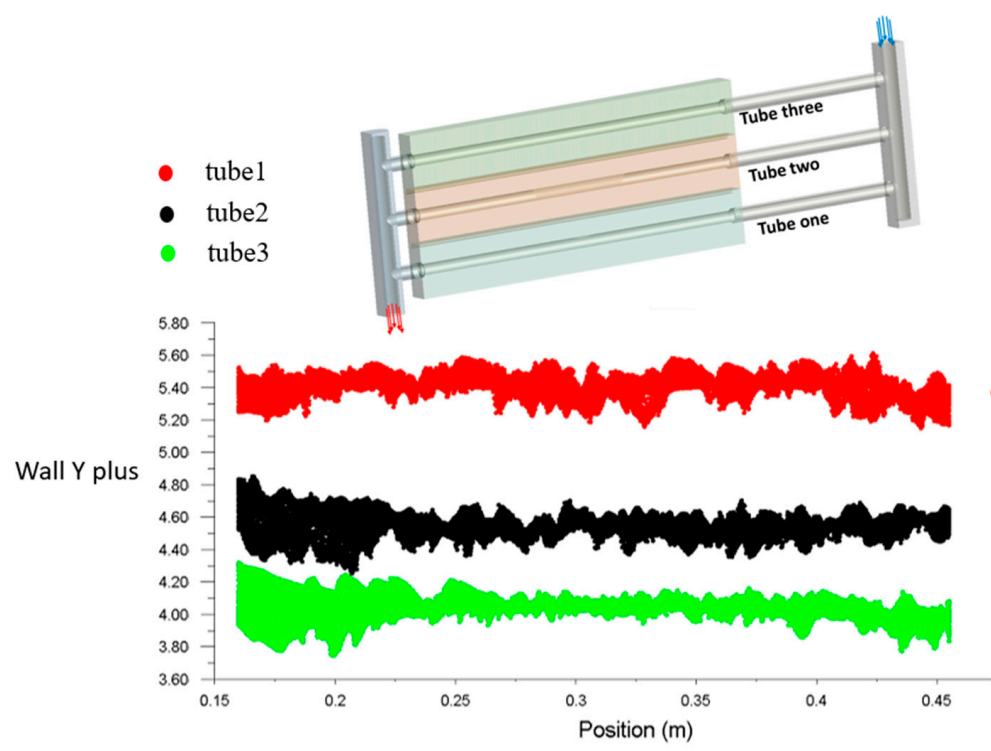

Figure 8. The y plus varying with the length of the cooling tubes.

The temperature field and the structure equivalent (Von Mises) stress of entrance collimator at the 100th second are shown in Figures 11 and 12. After the heat loaded for $100 \mathrm{~s}$, the maximum temperature of the heat flux loaded surface is only $333 \mathrm{~K}$; the corresponding heat transfer performance is greatly improved. The maximum structure equivalents (Von Mises) stress at the 100th second of oxygen free copper (plate structure) and stainless steel (branch pipe and support) are $45 \mathrm{MPa}$ and $25 \mathrm{MPa}$, respectively, which are all less than the upper limitation. While, in the Figure 12, it could be found that the maximum stress appears at the fixed position on both sides of the copper plate, if the heat 
flux continues to increase, the stress at this position will increase sharply, so in the future, if the operating heat flux exceeds more than the current working condition, the stress at this position may be more than now.

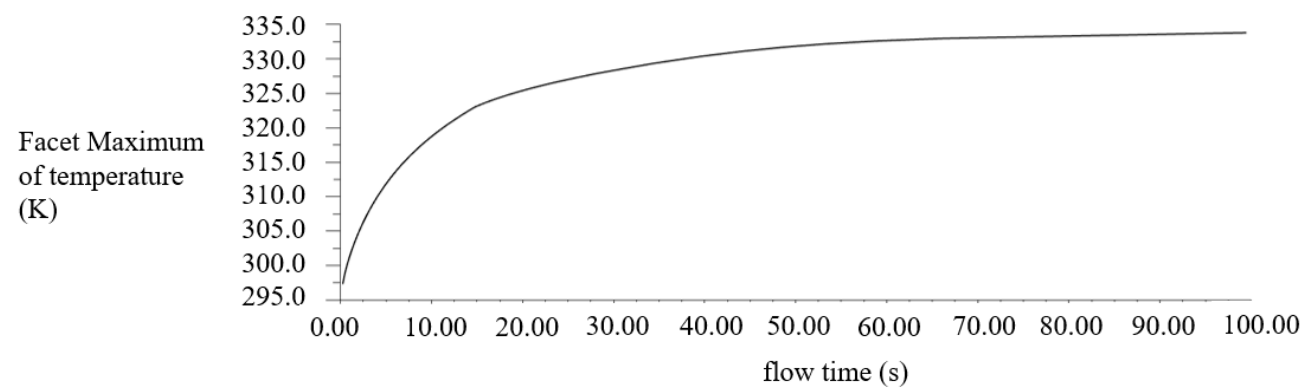

Figure 9. The maximum temperature of the heat-loaded surface of the entrance collimator varying with the pulse length.

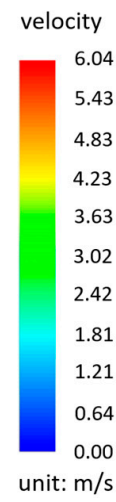

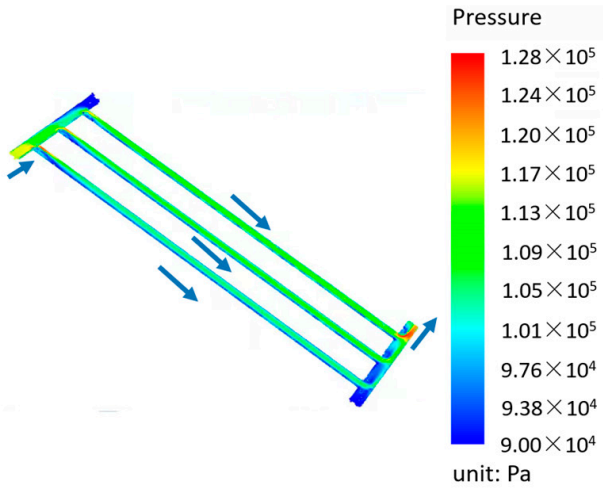

(a)

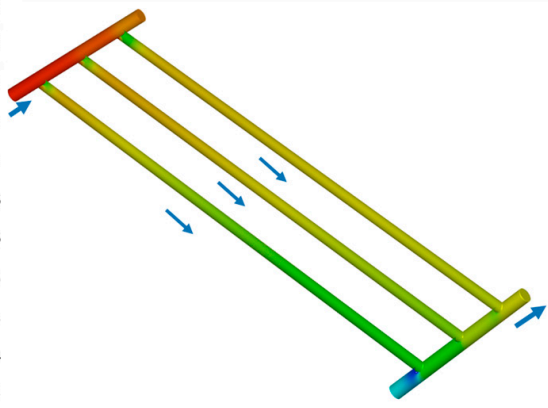

(b)

Figure 10. Velocity of fluid and pressure drop of the redesign scheme at the end of pulse length $100 \mathrm{~s}$ (entrance collimator): (a) Velocity of cooling water in the cooling tube; (b) pressure drop along the cooling tube.

To sum up, the new entrance collimator structure can better meet the cooling requirements of the $100 \mathrm{~s}$ pulse length operation under the current beam operating conditions, with low surface temperature rise and low stress, and has the potential for longer pulse time operation.

Static Temperature
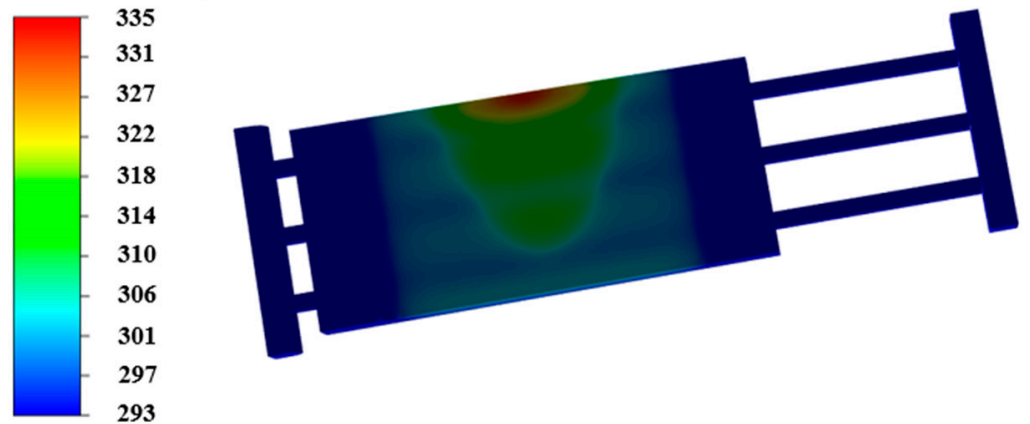

(K)

Figure 11. The temperature field of entrance collimator (at the 100th second). 


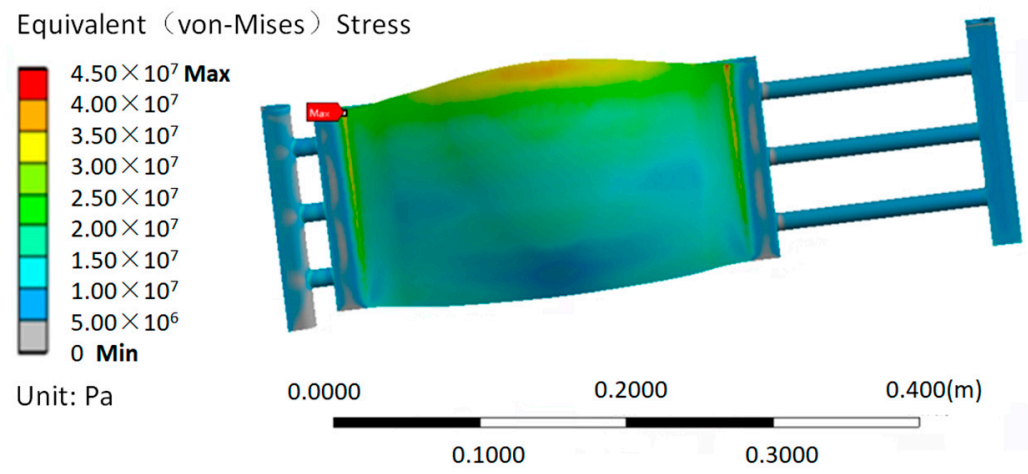

Figure 12. Structure equivalent (Von Mises) stress (at the 100th second).

\section{Conclusions}

In this paper, the structures of DM entrance and exit collimators which seriously restrict the long pulse operation of the EAST-NBI system during the experiment are redesigned based on the parallel arrangement of multiple rows of tubes. The effects of the tube bundle diameters, the number of tube rows and the inlet velocity on heat transfer performance and structural strength of the design scheme are considered, and the design parametric optimization together with the thermal-fluid-structure analysis was given. Take the entrance collimator for example, the results of the thermal-mechanical analysis verifies the feasibility of the proposed optimized design; the surface temperature rise and structure equivalent stress of the redesigned beam collimator have been well controlled and meet the requirements of long pulse operation. This research provides important theoretical and technical support for the development of heat enhancement performance of components in the NBI system and has important engineering value. At present, the optimized entrance and exit collimators have been processed and installed in the NBI system in ASIPP and are waiting for the next round of experiment to further verify the feasibility of the structure.

Author Contributions: Conceptualization, L.T. and C.H.; methodology, L.T. and L.L.; software, L.T.; validation, L.T., Y.X., C.H., W.Y. and L.L.; formal analysis, L.T.; resources, L.T. and L.L.; writing-original draft preparation, review and editing, L.T.; visualization, C.H.; supervision, Y.X. and C.H.; project administration, Y.X. and C.H.; funding acquisition, L.T. and Y.X. All authors have read and agreed to the published version of the manuscript.

Funding: This research was funded by National Natural Science Foundation of China No.11605234, National Key R\&D Program of China (Contract No. 2017YFE300103, 2017YFE300101).

Institutional Review Board Statement: Not applicable.

Informed Consent Statement: Not applicable.

Data Availability Statement: Not applicable.

Acknowledgments: The authors are very grateful to the other members of ASIPP NBI team for their continuous support and excellent work.

Conflicts of Interest: The authors declared that they have no conflict of interest to this work. We do not have any commercial or associative interest that represents a conflict of interest in connection with the work submitted.

\section{References}

1. Zhang, H.S. Ion Source and High Power Neutral Beam Source; Atomic Energy Press: Beijing, China, 1987.

2. Liang, L.Z. The Study of Beam Transmission in Magnetic Deflection System for Neutral Beam Injector. Ph.D. Thesis, Hefei Institutes of Physical Science, Chinese Academy of Sciences, University of Chinese Academy of Sciences, Beijing, China, 2011.

3. Spanier, A.; Hartmann, D.; Kslompolo, S.; Ford, O.; Wolf, R.C. Performance of the first neutral beam injector at the wendelstein 7-x stellarator. Fusion Eng. Des. 2021, 163, 112115. [CrossRef]

4. Ferro, A.; Lucchini, F.; Agostinetti, P.; Ratti, D.; Princiotta, A. Conceptual design of the power supplies for DTT neutral beam injector. Fusion Eng. Des. 2021, 169, 112624. [CrossRef] 
5. Khodak, A.; Titus, P.; Zatz, I.; Nagy, A.; Winkelman, J.; Nazikian, R.; Scoville, T. DIII-D neutral beam pole shields design including copper plate with removable molybdenum insert. Fusion Sci. Technol. 2015, 68, 355-373. [CrossRef]

6. Hu, C.D.; NBI Team. Conceptual Design of Neutral Beam Injection System for EAST. Plasma Sci. Technol. 2012, 6, 567-572. [CrossRef]

7. Lizhen, L.; Chundong, H.; Yuanlai, X.; Jianglong WE, I.; Yahong XI, E.; Jun, L.I. Design of the reflection magnet and its shielding effect analysis for the neutral beam injector of EAST. Nucl. Sci. Tech. 2011, 22, 70-76.

8. Hu, C. Achievement of 100 s Long Pulse Neutral Beam Extraction in EAST Neutral Beam Injection. Plasma Sci. Technol. 2013, 15, 5-7. [CrossRef]

9. Ezato, K.; Suzuki, S.; Dairaku, M.; Akiba, M. Critical heat flux experiments using a screw tube under DEMO divertor-relevant cooling conditions. Fusion Eng. Des. 2008, 83, 1097-1101. [CrossRef]

10. Lim, J.H.; Lee, S.W.; Oh, H.; Park, M.; Hwang, D.; Kim, M.H.; Jo, H. Heat-transfer characteristics of screw tube in one-side high heat load condition for fusion reactor divertor application. Int. J. Adv. Nucl. React. Des. Technol. 2021, 3, 213-225. [CrossRef]

11. Guamán, S.O.; Hanke, S.; Sartori, E.; Dalla Palma, M. Analysis of twisted tape solutions for cooling of the residual ion dump of the ITER HNB. Fusion Eng. Des. 2016, 109-111, 437-442. [CrossRef]

12. Dalla Palma, M.; Pasqualotto, R.; Sartori, E.; Tinti, P.; Zaccaria, P.; Zaupa, M.; Krilov, A.; Panasenkov, A.; Blatchford, P.; Canamero, J.F.M.; et al. The beamline for the ITER heating neutral beam injectors: A case study for development and procurement of high heat flux components. Fusion Eng. Des. 2021, 171, 112559. [CrossRef]

13. Ling, T.; Chundong, H.; Yuanlai, X.; Yongjian, X. Engineering design of ion dump for EAST neutral beam injection system. High Power Laser Part Beams 2013, 25, 2687-2692. [CrossRef]

14. Wang, W.; Khodak, A.; Zatz, I.; Nagy, A.; Titus, P. Shaping the aperture of the absolute collimator in DIII-D neutral beamline. Fusion Sci. Technol. 2019, 75, 828-834. [CrossRef]

15. Liu, F.B.; Yao, D.M. Thermo-Mechanical Analysis of CLAM Steel and SS316L in the First Wall for ITER. Mater. Sci. Forum 2011, 675-677, 917-920. [CrossRef]

16. Kwon, S.; Park, J.S.; Im, D.K. Thermo-mechanical evaluation of a water cooled high heat flux unit for the K-DEMO divertor. In Proceedings of the 2015 IEEE 26th Symposium on Fusion Engineering (SOFE), Austin, TX, USA, 31 May-4 June 2016.

17. Peng, X.B.; Bykov, V.; Köppen, M.; Ye, M.Y.; Fellinger, J.; Peacock, A.; Smirnow, M.; Boscary, J.; Tereshchenko, A.; Schauer, F. Thermo-mechanical analysis of Wendelstein 7-X plasma facing components. Fusion Eng. Des. 2013, 88, 1727-1730. [CrossRef]

18. De Muri, M.; Cavallin, T.; Pasqualotto, R.; Dalla Palma, M.; Cervaro, V.; Fasolo, D.; Franchin, L.; Tollin, M.; Greuner, H.; Serianni, G.; et al. High energy flux thermo-mechanical test of 1D-carbon-carbon fibre composite prototypes for the SPIDER diagnostic calorimeter. Rev. Sci. Instrum. 2014, 85, 02A718. [CrossRef] [PubMed]

19. Mistry, C.; Venkatanagaraju, M.; Rotti, C.; Pillai, S.; Bandyopadhyay, M.; Chakraborty, A.K. Fatigue based design and thermomechanical analysis of heat transfer element (HTE) for second calorimeter of Indian test facility (INTF). Fusion Eng. Des. 2017, 125, 64-70. [CrossRef]

20. Wei, J.; Zhang, Z.; Yi, W.; Tao, L.; Liang, L.; Xie, Y.; Hu, C. Thermo-mechanical design of the neutralizer for CRAFT negative ion-based neutral beam injection system. Fusion Eng. Des. 2021, 169, 112482. [CrossRef]

21. Chen, P.; Ye, M.; Peng, X.; Song, Y.; Mao, X. Preliminary Thermo-hydraulic and Mechanical Analysis for CFETR Divertor. J. Fusion Energy 2015, 34, 901-904. [CrossRef]

22. Tao, L. Design of High-Heat-Flux Components for EAST Neutral Beam Injection System with High Power and Long Pulse. Ph.D. Thesis, Hefei Institutes of Physical Science, Chinese Academy of Sciences, University of Chinese Academy of Sciences, Beijing, China, 2013.

23. Rollet, M.P.; Laurence, D.; Ferziger, J. LES and RANS of turbulent flow in tube bundles. Int. J. Heat Fluid Flow 1999, 20, $241-254$. [CrossRef]

24. Long, T.Y. Computational Fluid Dynamics; Chongqing University Press: Chongqing, China, 2007.

25. Incropera, F.P.; Lavine, A.S.; DeWitt, D.P. Fundamentals of Heat and Mass Transfer, 7th ed.; John Wiley \& Sons: New York, NY, USA, 2011.

26. Xu, T.J. Thermal-Hydraulic Design, Analysis and Experiment Research on EAST Divertor. Ph.D. Thesis, Hefei Institutes of Physical Science, University of Chinese Academy of Sciences, Chinese Academy of Sciences, Beijing, China, 2013. 